\title{
Evaluation of the seismic retrofitting of an unreinforced masonry building using numerical modeling and
} ambient vibration measurements

\author{
Clotaire Michel $^{\mathrm{a}}$, Amin Karbassi ${ }^{\mathrm{b}}$, Pierino Lestuzzi ${ }^{\mathrm{b}}$ \\ ${ }^{a}$ Swiss Federal Institute of Technology Zurich (ETHZ), Sonneggstrasse 5, 8092 Zürich, Switzerland \\ ${ }^{b}$ Ecole Polytechnique Fédérale de Lausanne (EPFL), Station 18, CH-1015 Lausanne, Switzerland \\ Originally published in Engineering Structures, 158, 124-135, March 2018. doi:10.1016/j.engstruct.2017.12.016
}

\begin{abstract}
Ambient vibration measurements and 3-D nonlinear time-history numerical modeling are used to assess the retrofitting measures conducted in a 6-story unreinforced masonry building (URM) built in the end of the $19^{\text {th }}$ century in Switzerland. Retrofitting measures were taken in order to improve the soundproofing and possibly the seismic performance of the building. Reinforced concrete (RC) footings were added under the walls and horizontal steel beams were added to link the walls together with a RC slab at each floor, though the wooden beams were left in place. Several ambient vibration recordings were performed before, during and after the retrofitting work in order to monitor the evolution of the dynamic behavior of the structure. Moreover, numerical models representing the state of the building before and after the retrofit work have been developed to perform nonlinear dynamic analyses using various ground motion records. The change in the modal vibration frequencies, mode shapes, and failure mechanism are presented and discussed in further details. According to ambient vibration measurements, the performed retrofitting resulted in an increase of about $25 \%$ of the fundamental frequency. From the results of both the numerical modeling and the ambient vibration measurements, it is confirmed that the in-plane behavior of the slabs evolved from non-rigid floors with in-plane deformation to rigid floors with diaphragm effects. The ambient vibration measurements show that the new stiff slabs could lead to torsion behavior in the building as the result of the diaphragm effect and to higher seismic demand. However, the numerical models show that the displacement capacity of the building increases as a result of those new stiff slabs. Consequently, higher deformation capacity, indicated by the inter-story drift values, on average, are observed for all the damage grades in the post-retrofit state of the building. Finally, the overall seismic safety was only slightly improved.
\end{abstract}

Keywords: seismic retrofitting; unreinforced masonry buildings; ambient vibration measurement; applied element method modeling; nonlinear time-history analysis; damage grade

\section{Introduction}

Since a large part of buildings around the World and especially in Northern Europe, were built without or with insufficient seismic provisions, seismic assessment of existing buildings is a critical and endless issue to be solved by earthquake engineering [1]. Cost-benefit approaches for the assessment and retrofit of existing buildings in Switzerland started to be used on a day-to-day basis in 2004 with the Pre-standard SIA2018 [2]. This Pre-standard provides guidelines on the measures to undertake to improve the seismic safety of a building taking into account the seismic risk, and in case, if retrofitting measures are commensurate. The results provided by the prescribed method are, however, quite rough, and the effects of an eventual retrofit needs to be more finely quantified.

Different seismic retrofitting measures have been proposed for unreinforced masonry (URM) buildings. Examples are: adding sandwich columns to partition brick walls [3], jacketing of columns, adding structural walls, and construction of a mat foundation [4], reinforced cement jacketing of the main load carrying walls [5] and using Fiber-Reinforced Polymers [6,7]. The effect of those retrofitting measures has been assessed using a variety of methods including Finite Element numerical modeling $[1,8]$ and vibration measurements [9]. One of the common measures to retrofit existing URM buildings in Europe is to create composite slabs by adding a reinforced-concrete (RC) layer over the existing wooden floor or even to replace it by a RC floor. This measure is generally proposed to improve the comfort and the soundproofing of the building, and is 
thought to be beneficial for the seismic behavior, as well. As a result, the masonry walls are linked together creating a diaphragm effect, which also prevents out-of-plane collapse of the walls [10,11].

This paper presents the evaluation of the retrofitting measures on a typical residential building in Switzerland [12]. The studied building is a 6-story simple stone unreinforced masonry building located in Lausanne Switzerland (Figure 1) built in the end of the $19^{\text {th }}$ century. The quality of masonry is poor since different bloc sizes and materials were used. The width of the walls varies from 25 to $70 \mathrm{~cm}$, and its average story height is $3 \mathrm{~m}$ (Figure 2). The mortar quality was also observed to be poor as it would crumble in hand under fingers' pressure. The structure is regular and not surrounded by any other building. The structural plan is rectangular ( $14 \mathrm{~m}$ by $12 \mathrm{~m})$, with wooden attics at the top ( $6^{\text {th }}$ floor) and thinner walls at the $5^{\text {th }}$ floor. Originally, no rigid diaphragm existed in the building, as shown in Figure 3a. Retrofitting measures were taken primarily in order to improve the soundproofing of the building. Qualitatively, these measures also aimed at improving the seismic safety. Horizontal steel beams were added at each floor to link the walls, together with a mixed slab, connecting the original wooden beams to a $7 \mathrm{~cm}$ thick RC slab (Figure 3). Moreover, one longitudinal wall that had not been fully connected to the wooden slab was carefully connected to the new RC slab. RC footings were added under the walls.

The foundation ground is made of a layer of moraine of likely 10-20m thickness laying on weathered Molasse rock [13]. The precise ground profile is unknown since the closest available profile is located $200 \mathrm{~m}$ away.

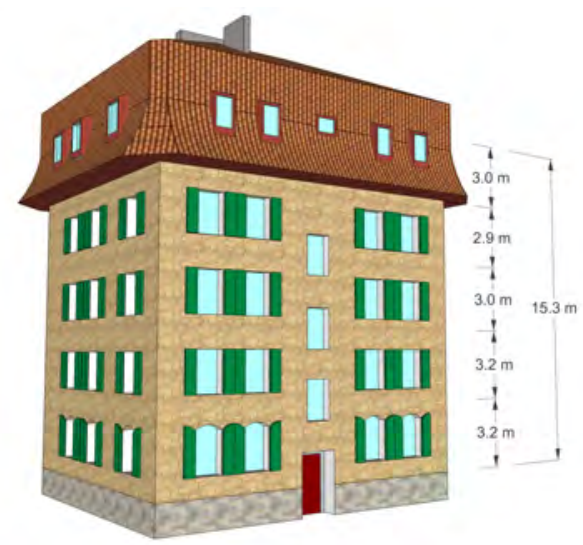

Figure 1. Studied unreinforced masonry residential building.

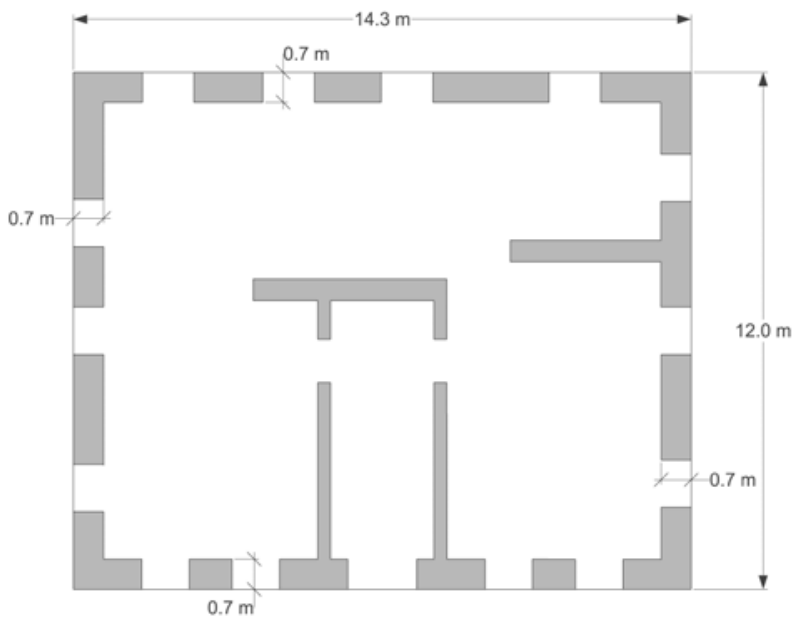

Figure 2. Plan view of the tested building with main dimensions. 


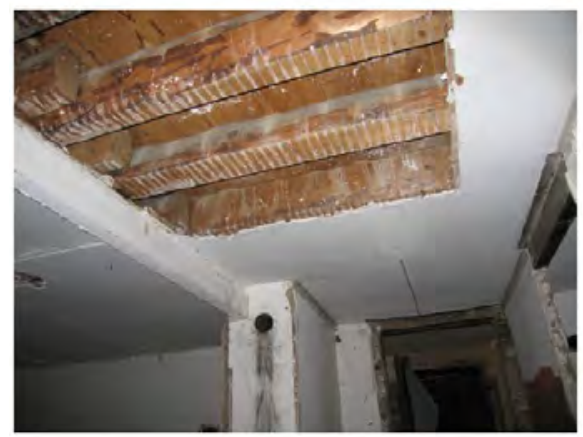

(a)

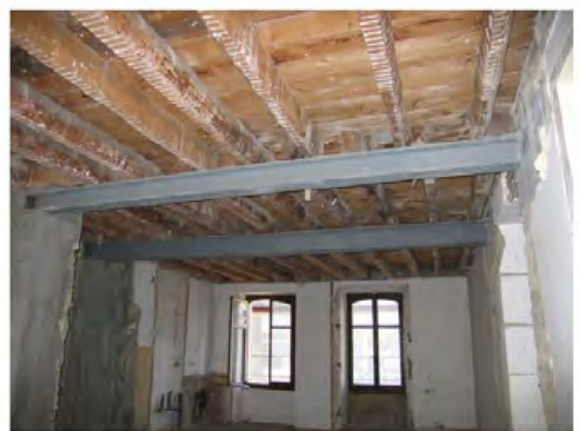

(b)

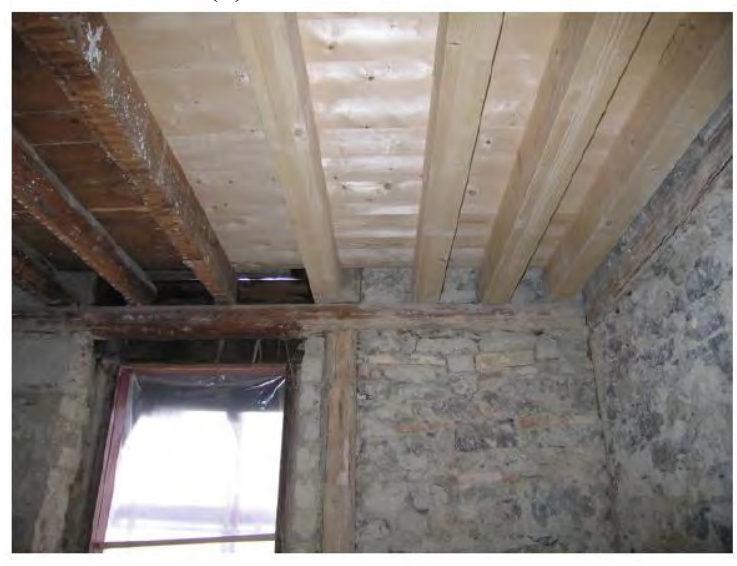

(c)

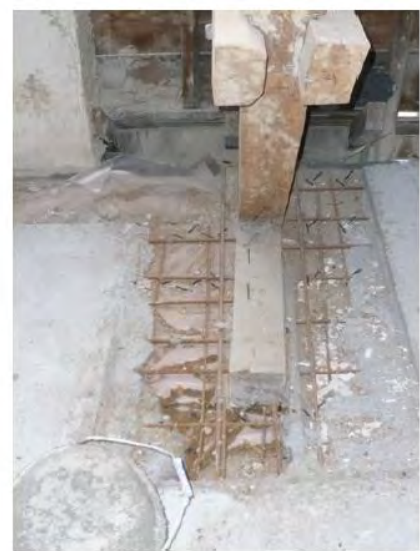

(d)

Figure 3. Retrofit of the slabs in the building (a) initial state, (b) added steel beams, (c) renewal of the wooden floors, and (d) added RC slabs

The method to assess the retrofitting work is based on two complementary techniques. Several ambient vibration recordings were performed before, during and after the retrofitting work in order to monitor the evolution of the dynamic behavior of the structure. Moreover, numerical models representing the state of the building before and after the retrofit work have been developed to perform nonlinear dynamic analyses using various ground motion records. Changes in the dynamic behavior should prove the effectiveness of the retrofitting, especially a change in the diaphragm effect. Using ambient vibrations, properties of the soil and features regarding soil-structure interaction can be evaluated, as well. These qualitative observations at low amplitudes are then used to validate [14,15], as realistic as possible, a non-linear numerical model using the Applied Element Method [16]. The numerical model provides the failure modes of the structure subjected to various ground motion records. Moreover, using many scenario earthquakes before and after the retrofitting measures, the safety of the structure is evaluated in both stages. It should be noted that, due to the simplifications in the numerical models and other uncertainties in the dynamic properties of structures, especially for URM buildings, no model updating (e.g. [15]) is undertaken in this study.

The objectives of this paper are to assess the effect of the retrofitting measures and to quantify the improvement in the seismic vulnerability of the building, which leads to the quantification of the gain in seismic safety. It aims at evaluating this retrofitting solution but does not provide a performance-based analysis for this particular case, i.e. for the local hazard. To this end, an original evaluation methodology is proposed based on in situ ambient vibration recordings and advanced nonlinear 3-D numerical modeling using Applied Element Method.

\section{Experimental modal analysis}

In order to evaluate in situ effect of the retrofit work in the URM building, we propose to compare the building's pre- and post-retrofit modal properties. Modal frequencies of civil engineering structures are synthetic measurable parameters that characterize the ratio of the stiffness of the structure over its mass. 
Since the mass of structure does not generally change much, they are used in Structural Health Monitoring to follow variations of the structural stiffness [17]. For retrofitting works, mass is generally added to the system (new RC slabs here), which complicates the interpretation. Moreover, modal shapes are directly sampling the structural behavior under a dynamic loading. Understanding this behavior (diaphragm effect, torsion, dominance of bending or shear) is crucial to validate hypotheses of numerical modeling.

For that purpose, operational modal analysis, based on ambient vibration (AV) recordings, is selected as it is easy to implement. Ambient vibrations result mainly from human activities (e.g., industrial machines, traffic) at frequencies above $1 \mathrm{~Hz}$ [18]. In addition to the quasi-stationary signals from those sources, transients such as footsteps close to a sensor could affect the stationary properties of the signals, and should be avoided in the analysis. Simultaneous recordings in the building, using a reference in a corner of the last floor and rover sensors are performed, as well as recordings on the ground, outside the building. Datasets of 15 to 30 minutes are recorded at different steps before, during and after the works.

The easiest way to obtain modal information from ambient vibration recordings is to calculate the Power Spectral Density (PSD), for instance using Welch method [19]. First, to make sure that only stationary signals are used, 50\% overlapping tapered time windows of the data are selected using an anti-triggering Short Time Average Long Time Average (STA/LTA) algorithm. Then, the Fourier Transforms of those windows are averaged and squared. The peaks in the spectra can be either due to ambient loading, internal sources or structural modes. Very sharp peaks can be ignored in the interpretation since they are due to un-damped forced motions that cannot be structural modes.

In order to extract the modal parameters of the structure (resonance frequencies, damping ratios and modal shapes) from ambient vibration recordings, the Frequency Domain Decomposition (FDD) [20] and the Enhanced Frequency Domain Decomposition [21] techniques, already extensively described and applied in the literature (e.g. $[14,22])$ are used in this paper. The proposed evaluation of the uncertainties on the peak position in the spectrum just includes the uncertainties due to the windowing process in the spectral estimation and no other possible sources of uncertainty such as natural variability or error due to the processing method. The uncertainty in the damping ratios arises from the choice of the fitted window in the logarithmic decrement method.

Moreover, using the recording in free field, the Horizontal to Vertical Spectral Ratios (HVSR) (e.g. [23]) can be used to detect the resonance frequencies of soil layers that may produce amplification of the ground motion. In this paper, the square root of the PSD spectra has been smoothed using the Konno and Ohmachi procedure [24] with a coefficient $b$ equal to 30 .

\subsection{Ambient vibration measurement settings}

A total number of four sets of measurements were conducted in the URM building. Figure 4 shows the configuration of the sensors in each of the measurement sets.

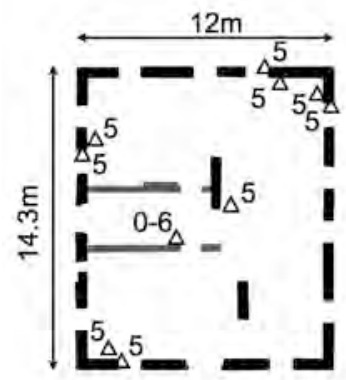

Test 1

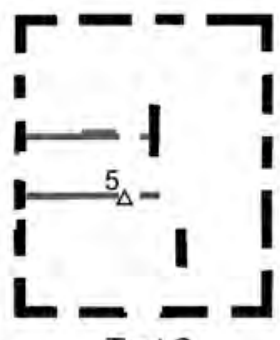

Test 2

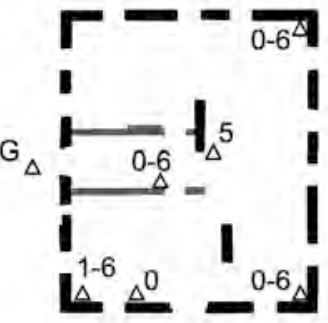

Test 3

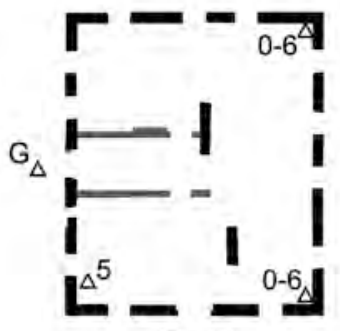

Test 4

Figure 4. Sensor layout (triangles) for the four AV tests. Numbers refer to the instrumented floor, G refers to ground (see Fig. 1). 
The first set of measurements was made before any retrofit work. The building was abandoned with gravel heaps at some places. During this test, 3 datasets were recorded, as shown in Table 1. The first dataset aimed at understanding torsion and deformation of the plan in the 5th story. In the second and third datasets, one point at each story in the staircase was recorded in order to determine the $1 \mathrm{D}$ vertical modal shapes. The reference sensor was set at the 5th floor (attics) in the staircase, close to the center of rotation. The amplitude of this point in torsion modes is small so that it is not a good reference point for torsion modes. The second set of measurements was made just after the cast of the RC slabs. At this time, the concrete had not yet reached its full stiffness, and light partition walls were also not in place. For this test, only one point at the top story was recorded. One month later, the third set of measurements was performed using 30 points in the whole structure, including 3 at the basement to eventually estimate soil-structure interaction, and one free field point. The reference sensor for this third set of measurements was set in a corner of the 5 th floor. Five months later, the fourth set of measurements was performed in 14 points, including one in free field. At the time of this fourth test, all the partition walls and new furniture was in place. The reference sensors at the 5th floor and in free field were the same as those in the third test.

Table 1. Recorded datasets in the URM building

\begin{tabular}{cccccc}
\hline Test & Date & Duration (sec.) & Samp. Freq. (Hz) & \# of datasets & \# of points \\
\hline 1 & $2008 / 05 / 28$ & 1800 & 200 & 3 & 16 \\
2 & $2009 / 03 / 05$ & 900 & 200 & 1 & 1 \\
3 & $2009 / 04 / 08$ & 900 & 200 & 7 & 30 \\
4 & $2009 / 09 / 25$ & 900 & 200 & 6 & 14
\end{tabular}

The signal of 6 Lennartz 3C 5s seismometers was recorded using a Cityshark 2 digitizer [25] for tests 1 and 3. In test 4 , four Lennartz 3C 1s sensors were used. Test 2 was done with a GeoSIG GBV316 seismological station, which includes a $3 \mathrm{C} 4.5 \mathrm{~Hz}$ geophone and a digitizer.

\subsection{Results from ambient vibration measurements}

The PSD spectra of a recording at the top of the structure (Figure 5a) show the evolution of the resonance frequencies during the retrofit work. In order to refine this analysis, FDD was used. The FDD spectra of all tests are presented in Figure $5 \mathrm{~b}$ and the interpreted results of the FDD analysis are summarized in Table 2.
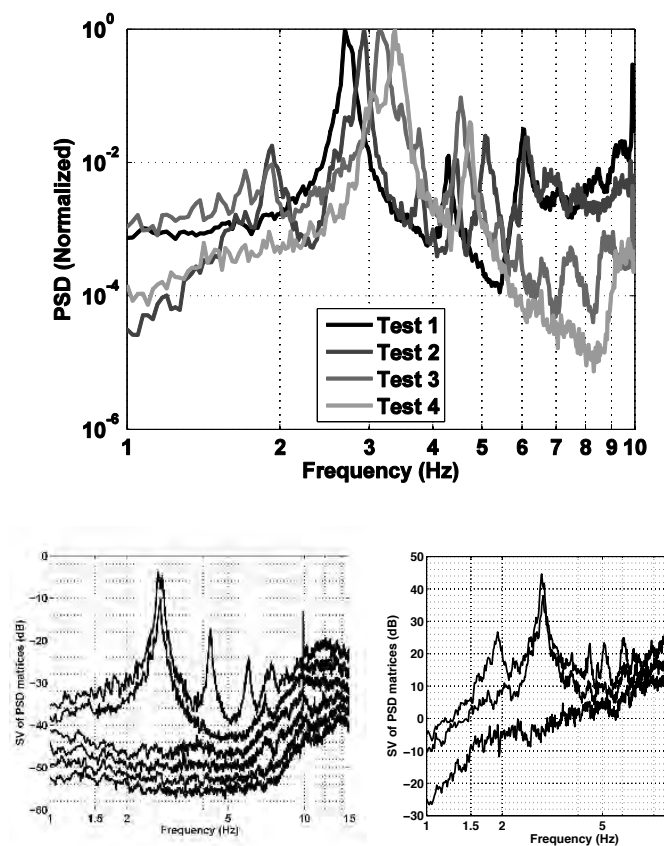

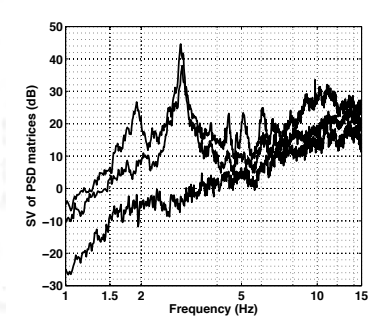

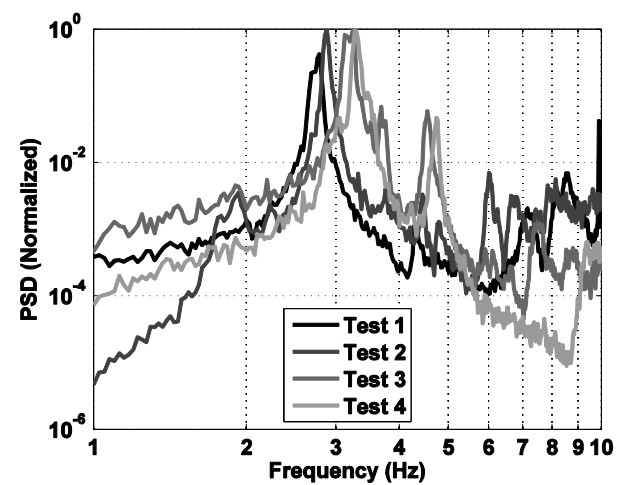

(a)
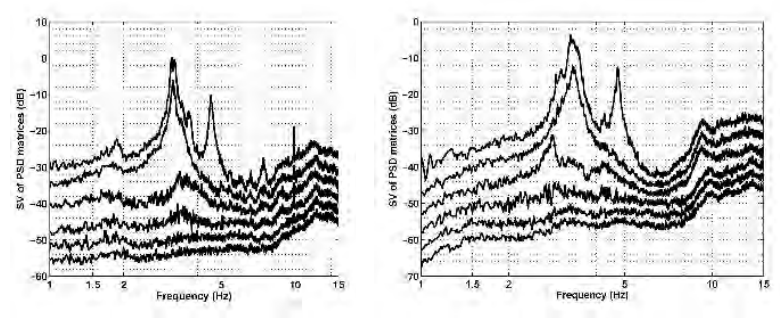

(b)

Figure 5. (a) Comparison of the PSD spectra of the 4 tests in the longitudinal and transverse directions and (b) FDD spectra of tests 1, 2, 3 and 4 
Table 2. Modes of vibration in the URM building from different sets of measurements $(\mathrm{ND}=\mathrm{Not}$ Determined)

\begin{tabular}{cclcc}
\hline Test & Mode & Interpretation & Freq. (Hz) & Damping ratio (\%) \\
\hline 1 & $1 \mathrm{st}$ & $1^{\text {st }}$ long. bending & $2.70 \pm 0.04$ & $1.0 \pm 0.4$ \\
2 & 2 nd & $1^{\text {st }}$ long. bending & $2.93 \pm 0.05$ & $0.6 \pm 0.2$ \\
3 & $1 \mathrm{st}$ & $1^{\text {st }}$ long. bending & $3.15 \pm 0.02$ & $0.6 \pm 0.2$ \\
4 & 2 nd & $1^{\text {st }}$ long. bending & $3.41 \pm 0.04$ & $1.6 \pm 0.3$ \\
\hline 1 & $2 \mathrm{nd}$ & $1^{\text {st }}$ trans. bending & $2.76 \pm 0.03$ & $1.0 \pm 0.4$ \\
2 & $1 \mathrm{st}$ & $1^{\text {st }}$ trans. bending & $2.87 \pm 0.03$ & $0.8 \pm 0.2$ \\
3 & $2 \mathrm{nd}$ & $1^{\text {st }}$ trans. bending & $3.22 \pm 0.03$ & $0.9 \pm 0.3$ \\
4 & $1 \mathrm{st}$ & $1^{\text {st }}$ trans. bending & $3.26 \pm 0.03$ & $2.5 \pm 1.0$ \\
\hline 1 & $3 \mathrm{rd}$ & $1^{\text {st }}$ torsion & $4.27 \pm 0.02$ & $1.1 \pm 0.2$ \\
2 & $3 \mathrm{rd}$ & $1^{\text {st }}$ torsion & $4.44 \pm 0.04$ & $\mathrm{ND}$ \\
3 & $3 \mathrm{rd}$ & $1^{\text {st }}$ torsion & $4.55 \pm 0.02$ & $1.3 \pm 0.1$ \\
4 & $3 \mathrm{rd}$ & $1^{\text {st }}$ torsion & $4.74 \pm 0.01$ & $1.1 \pm 0.2$ \\
\hline 1 & $4 \mathrm{th}$ & $2^{\text {nd }}$ trans. bending & $6.03 \pm 0.03$ & $1.6 \pm 0.3$ \\
1 & 5 th & $2^{\text {nd }}$ long. bending & $7.4 \pm 0.2$ & $3.5 \pm 0.3$ \\
3 & $4 \mathrm{th}$ & $2^{\text {nd }}$ torsion & $7.5 \pm 0.3$ & $\mathrm{ND}$ \\
\hline
\end{tabular}

The fundamental bending modes in the longitudinal and transverse directions (modes 1 and 2) are very close for each test. Therefore, the stiffness is nearly the same in both directions, whatever the retrofit state. The 3D modal shapes (not displayed here) are not fully decoupled, including a part of torsion. For tests 1 and 3, they are not decomposed following the main directions of the building but modal shapes are diagonal. This may be due to the modal analysis technique used. The frequency of the first longitudinal bending mode evolves from 2.7 in the initial state to $3.4 \mathrm{~Hz}$ at the end of the retrofit. For the transverse mode, this frequency increases from 2.8 up to $3.3 \mathrm{~Hz}$, therefore less than the frequency increase in the longitudinal direction. The increase in frequency means that the stiffness increase is greater than the mass increase during the retrofitting work. The increase in frequency reaches $25 \%$, corresponding to an increase of $60 \%$ in the stiffness over mass ratio. Since mass increased due to the additional RC slabs, stiffness increase is, therefore, even larger. This can be interpreted as a loss of flexibility (bending) due to the diaphragm effect and to the connection of a longitudinal wall that was disconnected from the wooden slab in the initial state, allowing all walls to resist lateral loads together. A $16 \%$ frequency increase occurred while the new stiff slabs were already installed (between tests 2 and 4 ) corresponding to $35 \%$ in the stiffness over mass ratio. If this period corresponds only to the installation of non-structural elements, it probably mainly includes long-term stiffening of the concrete. Moreover, the longitudinal direction is clearly stiffer $(10 \%)$ than the transverse one, which is interpreted as the connection of the additional wall, only for the last test. It is therefore not seen 1 month after these works, but only 6 months after, which confirms that long-term effects are involved. Only permanent monitoring would have allowed understanding these effects.

Although the uncertainties remain large, the damping ratio seems larger for the final state ( 1.6 and $2.5 \%$ for the longitudinal and transverse directions, respectively) compared to the others (around 1\%). The interpretation of damping ratio under ambient vibrations is however difficult. One possible explanation is the increase of radiation damping due to the new foundation.

The modal shapes of the first two modes are presented in Figure 6. Their shapes in elevation are similar in both directions. In test 1, the structural behavior is closer to the behavior of the Euler-Bernoulli (pure bending) beam that is typical for stone masonry buildings with timber floors [26]. In test 4, the modal shapes moved towards the pure shear beam behavior, as a result of a loss of flexibility, as previously explained. With the new stiff slabs, the distribution of strains changed from a cantilever to a shear beam. A negative aspect of this, however, is that the ground floor should, in the retrofitted state, sustain larger drifts for the same top displacement. 


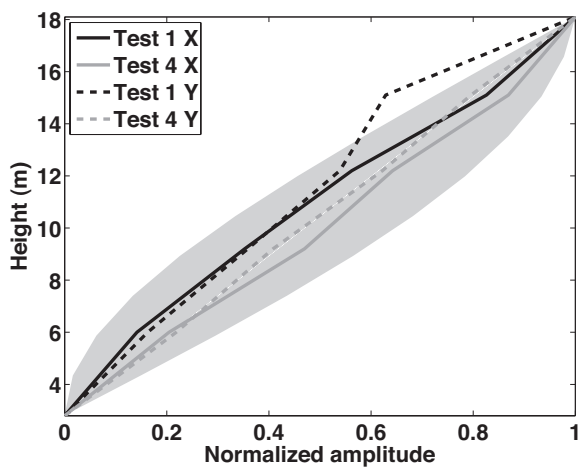

Figure 6. Comparison of the modal shapes in elevation between the first and the fourth test. The greyshaded area represents the area between the Euler-Bernoulli (pure bending, upper limit) and the pure shear

(lower limit) beams (see also [26])

Another important characteristic of the 3D modes is that, in the first test, they are pure translational, not coupled with any torsion, whereas in tests 3 and 4 , those modes show a small torsion component. This effect is certainly related to the diaphragm created by the stiff slabs that allow torsion to develop, whereas with the timber floors, torsion was inhibited by the deformations in the slabs. Since the building is regular in plan, and the center of rotation is indeed close to the center of mass, this effect may not have a great importance.

A closer look at the mode shape in the first test (before retrofitting, see Figure 7) indicates that there are internal deformations in the slab. This figure compares the experimental mode shape with a model assuming an average rigid body motion for the slabs. The timber slabs do not ensure the diaphragm effect, whereas in the third test, there are no more internal deformations thanks to the stiff slabs.

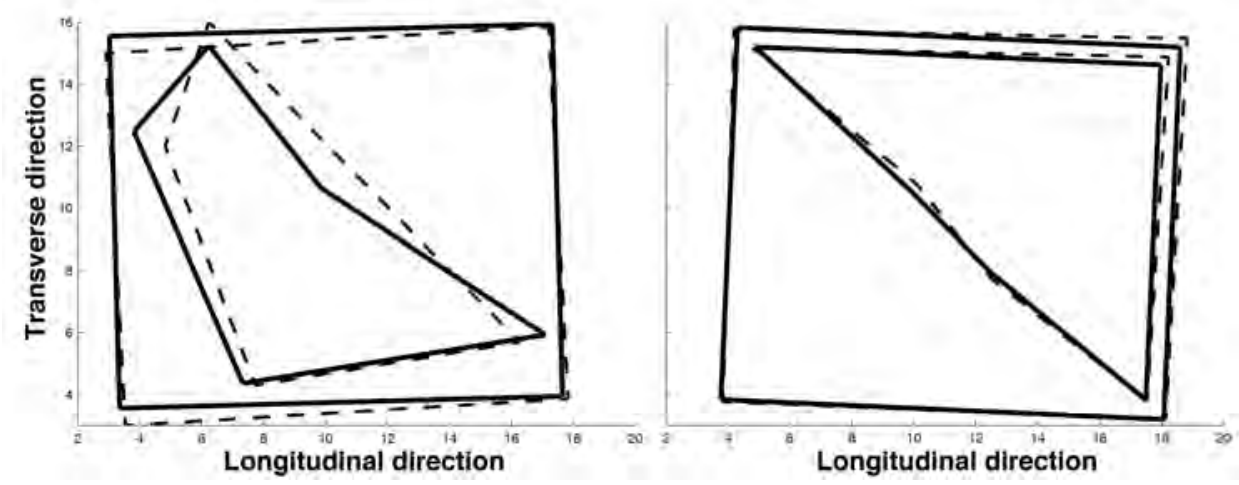

Figure 7. Second mode shape of the 5th story of the structure in test 1 (left) and 3 (right): the inner lines are arbitrarily connecting the recording points, whereas the outer rectangle represents the outer walls of the building. Dashed lines connect the points of the observed modal shape and solid lines correspond to an average rigid body motion of the slab assumed non-deformed

The third mode appears clearly to be a pure torsion mode in all tests, i.e. the mode associated with the rotational degree-of-freedom of the structure around its vertical axis. The frequency of this mode evolves from 4.3 in the initial state to $4.7 \mathrm{~Hz}$ at the end of the retrofit, following the same trend as the first two modes. The increase in frequency, however, is lower than for the previous modes.

Several upper modes have been detected in tests 1 and 3 between 6 and $7.5 \mathrm{~Hz}$. The observed modes are different from one test to another. They do not bring additional information in this case.

\subsection{Ground amplification and soil-structure interaction}

The Horizontal to Vertical spectral ratios (HVSR) were computed for recordings on the ground in order to determine eventual resonance frequencies of the ground. The results for test 1 at the basement and test 3 and 4 in "free field" are displayed in Figure 8. The results are consistent from one test to another. The variations 
in the amplitude of the peak can be due to the wavefield and cannot be interpreted as a change in structural properties.

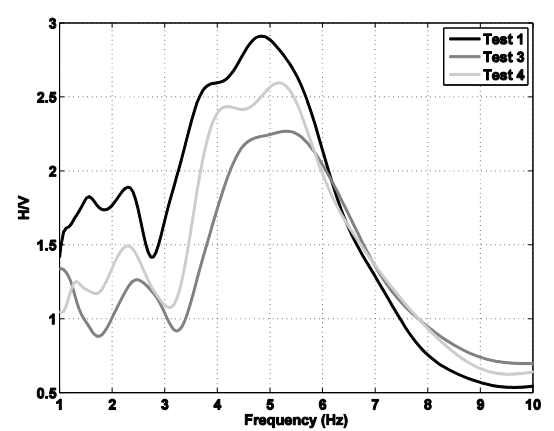

Figure 8. Horizontal to Vertical Spectral Ratios of the soil recordings of the first, third and fourth tests

In all cases, a peak at $5 \mathrm{~Hz}$ is clear in the spectral ratios. The peak amplitude is moderate and the peak is wide. According to boreholes in the surroundings, the ground is made of a 10 to $20 \mathrm{~m}$ thick layer of moraine on Molasse rock [13]. Therefore, the peak at $\mathrm{f}_{0}=5 \mathrm{~Hz}$ in the $\mathrm{H} / \mathrm{V}$ ratios is likely associated to the resonance of the layer of moraine. Using the classical equation $\mathrm{f}_{0}=\mathrm{V}_{\mathrm{s}} / 4 \mathrm{H}$ and considering an average shear wave velocity of $V_{\mathrm{s}}=290 \mathrm{~m} / \mathrm{s}(+/-30 \mathrm{~m} / \mathrm{s})$ as proposed in [13], the thickness of the upper layer $\mathrm{H}$ would be between 13 and $16 \mathrm{~m}$, which is coherent. The fundamental frequency of the soil is, therefore, distant from the building's fundamental frequency; therefore, it should not significantly increase the seismic demand on the building.

The small peak at $2.5 \mathrm{~Hz}$, seen in Figure 8 , is clearly related to the structural behavior. We can also notice that this peak can be seen in the spectra in "free field", which means that the sensor was too close (about $2 \mathrm{~m}$ away) to the building to avoid soil-structure interaction (SSI).

The effect of SSI on the observations is difficult to assess simply. In any case, the stiffening of the structure due to retrofitting reduces the apparent frequency of the structure (see for instance [27]), but it is not clear if it is significant. However, in case it would be significant, SSI would have limited the increase in the apparent frequency of the structure and the fixed-base frequency might have increased more than what is observed. It is important to note that soil-structure interaction effects are not included in the numerical modeling performed in the following due to the increased complexity in the model involved.

\section{Numerical modeling of unreinforced masonry structures}

The nonlinear dynamic analyses in this paper are performed using the Applied Element Method. This method, which is based on dividing structural members into virtual elements connected through springs (no common nodes unlike Finite Element Method) can simulate large displacements and elements progressive separation through successive failure of those springs [28]. It is shown previously that AEM numerical modeling has the ability to simulate in-plane and out-of-plane failure modes in masonry units and in masonry structures due to static and dynamic loadings [16].

In a time-history structural analysis, the calculated responses are sensitive to the characteristics of the individual ground motion used as the seismic input. Therefore, different ground motion records are required to obtain a good estimation of the building's responses. In order to use the Applied Element Method in the nonlinear dynamic procedure, large deformations of an element under dynamic loads are calculated by the following general dynamic equation of motion [29].

$$
\left.[M] \mid \Delta U^{\prime \prime}\right]+[C]\left[\Delta U^{\prime}\right]+[K][\Delta U]=[\Delta f(t)]+\left[R_{m}\right]+\left[R_{G}\right]
$$

In Equation $1,[M]$ is the mass, $[C]$ is the damping, and $[K]$ is the stiffness matrix. Moreover, $\Delta f(t)$ is the incremental applied load vector, $[\Delta U]$ is the incremental displacement vectors, and $\left[\Delta U^{\prime}\right]$ and $\left[\Delta U^{\prime \prime}\right]$ are the incremental velocity and acceleration vectors, respectively. For the sake of simplicity only the horizontal components of motion are used though the vertical component may be critical in some cases such as the 2011 Christchurch event [30]. The vector $R_{m}$ in Equation 1 stands for the residual forces caused by cracking, or 
the incompatibility between strains and stresses at the spring location due the nonlinear behavior of materials. The vector $\mathrm{R}_{\mathrm{G}}$, on the other hand, represents the residual forces caused by geometrical changes of the structure during loading. The nonlinear material behavior in the AEM is taken into account in calculating $[\mathrm{K}]$ and $\mathrm{R}_{\mathrm{m}}$. The constitutive model for unreinforced masonry in AEM is based on damage mechanics and takes into account both the mortar damage and brick-mortar de-cohesion, which is considered to take place when opening and frictional sliding are activated. Constitutive property of joint springs is based on two damage variables representing frictional sliding and mortar joint damage. Those variables are obtained from MohrCoulomb's friction surface and damage condition based on fracture mechanics [31].

\subsection{Definition of damage grades for the unreinforced masonry building}

To conduct the seismic vulnerability evaluation for the studied building, a clear definition of the damage grades is essential [32]. The EMS-98 [33] damage scale is used here to determine the limit states of different damage levels from the dynamic analyses. Table 3 presents the description of those damage grades for unreinforced masonry buildings.

Table 3. Damage grades for URM buildings according to EMS-98 [33]

\begin{tabular}{cl}
\hline $\begin{array}{c}\text { Damage } \\
\text { Grade }\end{array}$ & \multicolumn{1}{c}{ Description of damages } \\
\hline D1 & $\begin{array}{l}\text { Negligible to slight damage: no structural damage and/or slight non- } \\
\text { structural damage }\end{array}$ \\
D2 & $\begin{array}{l}\text { Moderate damage: slight structural damage and/or moderate non-structural } \\
\text { damage }\end{array}$ \\
D3 & $\begin{array}{l}\text { Substantial to heavy damage: moderate structural damage with heavy non- } \\
\text { structural damage. }\end{array}$ \\
D4 & $\begin{array}{l}\text { Very heavy damage: heavy structural damage and/or very heavy non- } \\
\text { structural damage. }\end{array}$ \\
D5 & Destruction (very heavy structural damage): total or near total collapse. \\
\hline
\end{tabular}

Considering that the descriptions in Table 3 depend mainly on the expert judgement to determine the damage grades, physical interpretations of those damage grades [34], as shown in Table 4, are used in this paper, alternatively (see section 3.3).

Table 4. Description of EMS-98 damage grades for URM according to Lang [34]

\begin{tabular}{ll}
\hline $\begin{array}{l}\text { Damage } \\
\text { Grade }\end{array}$ & \multicolumn{1}{c}{ Description of damages } \\
\hline D1 & First wall reaching the onset of tensile cracking \\
D2 & First wall reaching the yield displacement \\
D3 & Slope of the capacity curve tends \\
D4 & to zero (Yielding in majority of the walls) \\
D5 & Failure of the first wall \\
\hline
\end{tabular}

\subsection{Numerical models before and after retrofitting}

For the studied URM building, a total number of 5 springs is used on each face of the elements. The size of the meshing is selected to avoid creating elements with large aspect ratios. To this end, an approximate number of $22^{\prime} 500$ elements are used in the numerical models. Two numerical models are developed for the two states of the building, pre-retrofit and post-retrofit, as shown in Figure 9. It should be noticed that in Figure 9a, the wooden slab at the top floor is hidden to show a better view of the timber beams, which simply sit on the URM walls. 


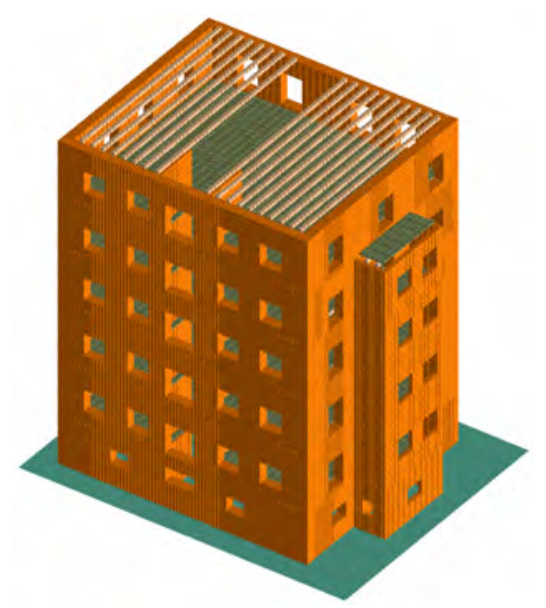

(a)

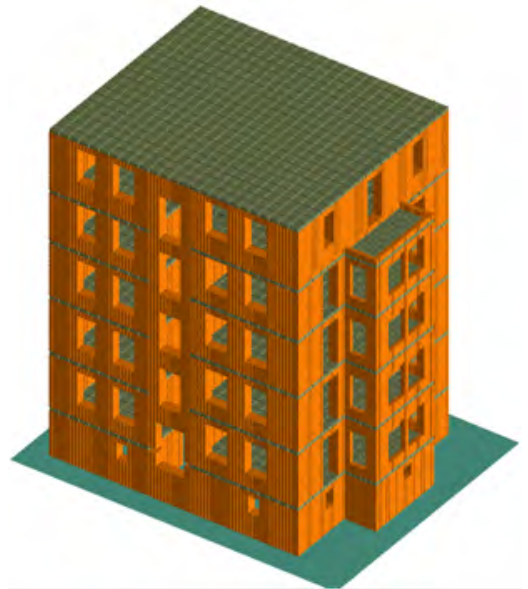

(b)

Figure 9. Numerical models for the URM building (a) before and (b) after the retrofit work

\subsubsection{Masonry unit properties in the numerical models}

Table 5 presents design properties for masonry units from different references.

Table 5. Masonry unit design properties (SIA266: SIA, 2003; SIA2018: SIA, 2004; EC-6: CEN, 2005)

\begin{tabular}{|c|c|}
\hline$E_{m}$ modulus of elasticity & $1000 \mathrm{f}_{\mathrm{xd}}$ (SIA266 [35], EC-6 [36]) \\
\hline$f_{x d}$ compression strength $(\mathrm{MPa})$ & $2-5.5($ SIA266 [35], SIA2018 [2]) \\
\hline$f_{y d}$ compression strength $(\mathrm{MPa})$ & $0.3 f_{x d}-0.5 f_{x d}$ SIA266 [35]) \\
\hline$f_{t d}$ tensile strength $(\mathrm{kPa})$ & $150-350[37]$ \\
\hline
\end{tabular}

According to the Swiss Standard SIA 266 [35]:

$$
f_{x k}=\frac{\gamma_{m}}{\eta_{1} \cdot \eta_{2}} f_{x d}
$$

where $f_{x k}$ and $f_{x d}$ are the characteristic and design strength values perpendicular to bed joints, respectively. $\gamma_{\mathrm{m}}$ is the partial factor taking into account the approximation of the resistance model, as well as the differences in material properties compared to their characteristic values. $\eta_{1}$, on the other hand, is the conversion factor taking into account the decrease of $f_{x d}$ in the header and stretcher masonry. Finally, $\eta_{2}$ is the conversion factor to consider the increase in $f_{x d}$ in case of a solicitation of a localized area. From the same reference, for the studied building, $\gamma_{\mathrm{m}}=2.0$, and $\eta_{1}=\eta_{2}=1.0$. Therefore:

$$
f_{k}=2 f_{d}
$$

According to Eurocode6 [36], characteristic values of masonry properties can be considered as the 5\% percentile of the expected values. Assuming a normal distribution for the material properties, we can assume Equation 4 for $f_{x k}$.

$$
f_{x k}=X_{5 \%}=\mu-1.65 \sigma
$$

where $\mu$ and $\sigma$ are the mean and standard deviation of the expected material properties. Considering a coefficient of variation $(\mathrm{COV})$ of 0.2 from the literature:

$$
\mu=1.98 f_{x k}=3.96 f_{x d}
$$

Replacing the values from Table 5 in Equation 5, the expected masonry unit properties that are used in the dynamic analysis are shown in Table 6 . It should be noted that the elastic modulus for masonry is reduced by $50 \%$ to consider the cracking in the masonry units in the existing buildings [34]. 
Table 6. Expected properties of Masonry units used in the dynamic analyses

\begin{tabular}{|c|c|}
\hline Masonry modulus of elasticity $(\mathrm{GPa})$ & 1.5 \\
\hline \multirow{2}{*}{ Compression strength $(\mathrm{MPa})$} & $10(\perp$ bed joints $)$ \\
& $4.2(\perp$ head joints $)$ \\
\hline Tensile strength $(\mathrm{MPa})$ & 0.75 \\
\hline
\end{tabular}

\subsubsection{Selection of the ground motion records}

The ground motion records used in this project are chosen from the European ground motion record database [38], the ITACA database [39] and the 21/02/2011 Christchurch Internet Data Report from the Center for Engineering Strong Motion Data. They are not related to a specific local hazard but chosen with a relatively uniform distribution of magnitudes and distances. The distance range is from 0 to $40 \mathrm{~km}$ and the magnitude from 4 to 7.1, in order to avoid completely unrealistic events for Switzerland. Table A-1 presents the detailed information of the characteristics of the 50 ground motions used in the nonlinear dynamic analyses. Figure 10 illustrates the distribution of the magnitude-distance to site for the ground motion records shown in Table A-1.

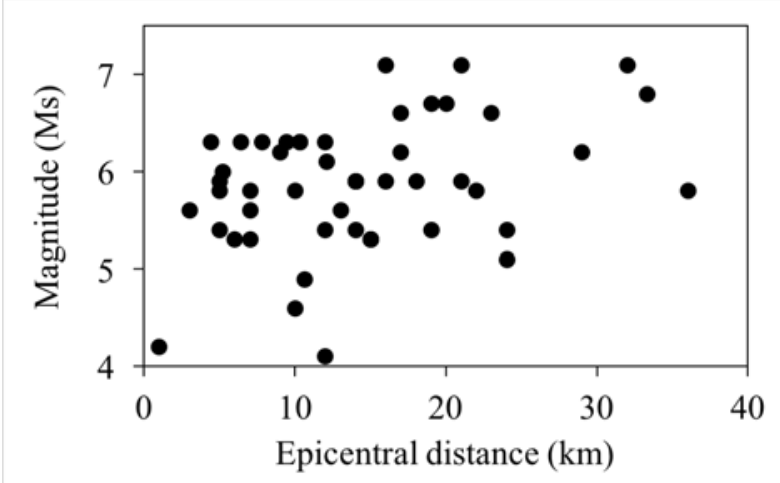

Figure 10. Magnitude-distance distribution of the ground motion records

A total number of 50 numerical analyses were performed for the building's models before and after the retrofitting work, using the ground motion records in Table A-1.

\subsection{Modal analysis and global failure modes}

The modal frequency values from the two numerical models representing the URM building before and after the retrofit work are shown in Table 7.

Table 7. Modal frequencies of the buildings from numerical modeling

\begin{tabular}{|l|c|c|}
\hline & before retrofit & after retrofit \\
\hline $1^{\text {st }}$ mode freq. (longitudinal) & $2.94 \mathrm{~Hz}$ & $3.03 \mathrm{~Hz}$ \\
\hline $2^{\text {nd }}$ mode freq. (transverse) & $3.13 \mathrm{~Hz}$ & $3.22 \mathrm{~Hz}$ \\
\hline
\end{tabular}

As it is seen in this table, there is about 3\% increase in the modal frequency of the building in each direction. This small increase, in spite of the installation of the stiff slabs, can be explained by the fact that there has been also an increase in the total mass because of those new slabs.

To identify the damage grades for each ground motion record, the descriptions in Table 4 are used to determine the status of the URM building at the end of each nonlinear dynamic analysis. This process is done visually and numerically by considering the state of stress/strain in the building. To this end, damage grade 1 occurs when first tensile cracking happens in a wall (Figure 11a). When the first wall in the building reaches the yielding point, the building is known to have reached damage grade 2 . As stated in Table 4, damage grade 3 happens when yielding occurs in the majority of walls in the building (Figure 11b). The collapse of the first wall in the building indicates that the building has reached damage grade 4 (Figure 11c). As the interior walls 
in the URM building have weak connections with the floors, damage grade 4 does not necessarily occur unless the collapse of those walls is accompanied by yielding in a majority of walls and/or heavy damage in other walls. Damage grade 5 happens when the building is on the edge of total collapse or has been destructed heavily. The URM building before and after the retrofit work shows completely different behavior when it reaches this damage grade. Using the numerical model, it is shown that the failure of the URM building before the retrofit work is governed by the out-of-plane failure of the walls which do not support the timber beams (Figure 12a) accompanied by the collapse of some of the spandrels. On the contrary, the URM building after the retrofit work collapses due to weak pier-strong spandrel damage mechanism. In this mechanism, the plastic displacement due to flexure or shear will be concentrated in the piers of the first floor which results in a soft story mechanism in the building (Figure 12b).

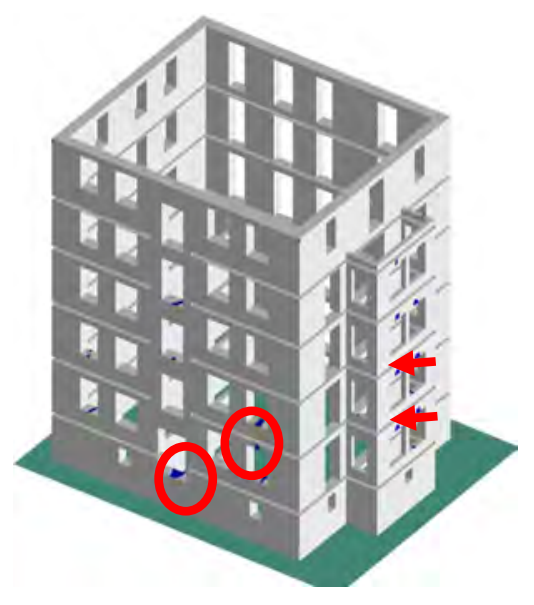

(a)

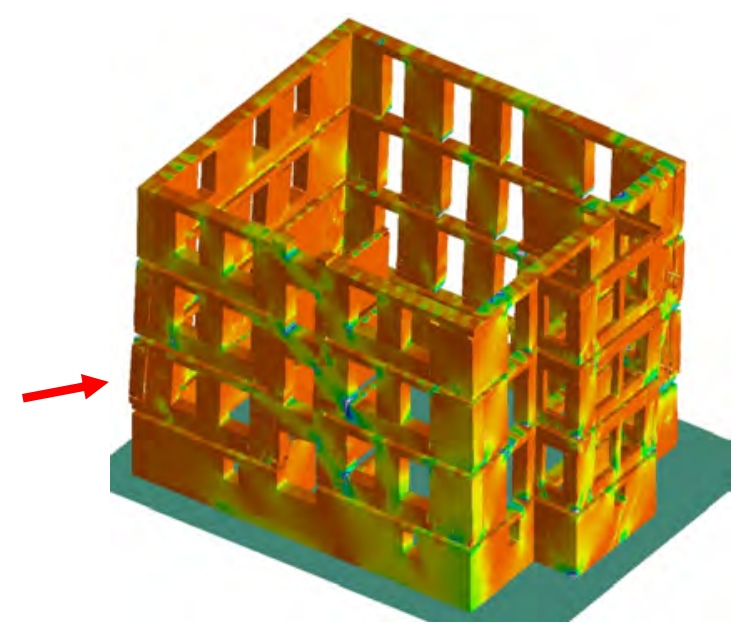

(c)

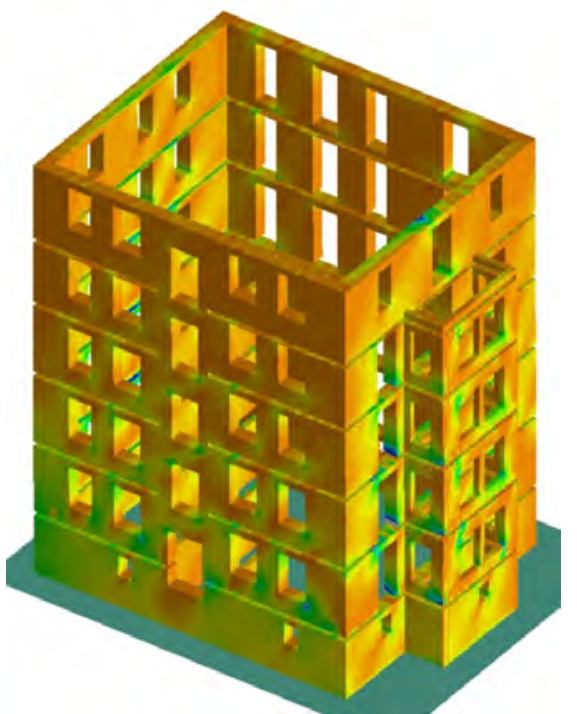

(b)

Figure 11. Typical damage mechanisms in the numerical model of the URM building before retrofitting associated to: (a) DG1, (b) DG3 and (c) DG4 


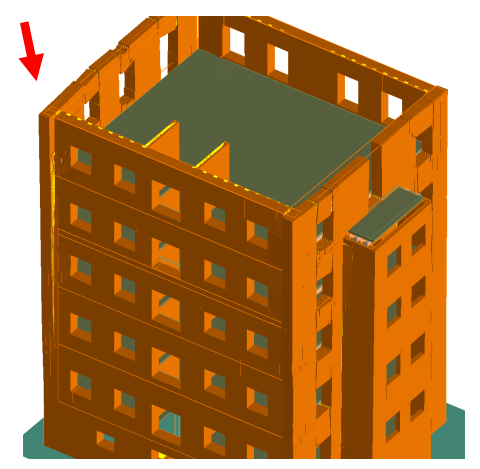

(a)

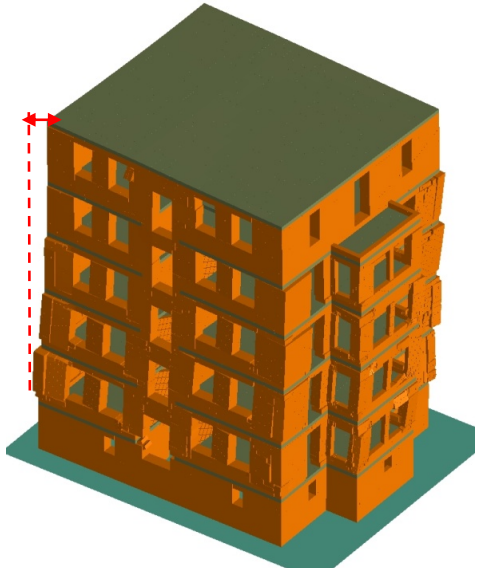

(b)

Figure 12. Typical damage mechanisms associated to DG5 in the numerical model of the URM building (a) before and (b) after retrofitting

Figure 13 shows the distribution of the damage grades with the peak ground acceleration of the ground motion records used for the nonlinear dynamic analyses. Considering that both components of the records were used simultaneously in the numerical analyses, PGA values shown in Figure 13 are the maximum value of the PGA in $\mathrm{X}$ and $\mathrm{Y}$ directions.

Among the simulations using the same ground motion before and after retrofitting, 17 simulations led to the same damage grade, 8 to a worsening of 1 damage grade and 10 to an improvement of 1 damage grade.
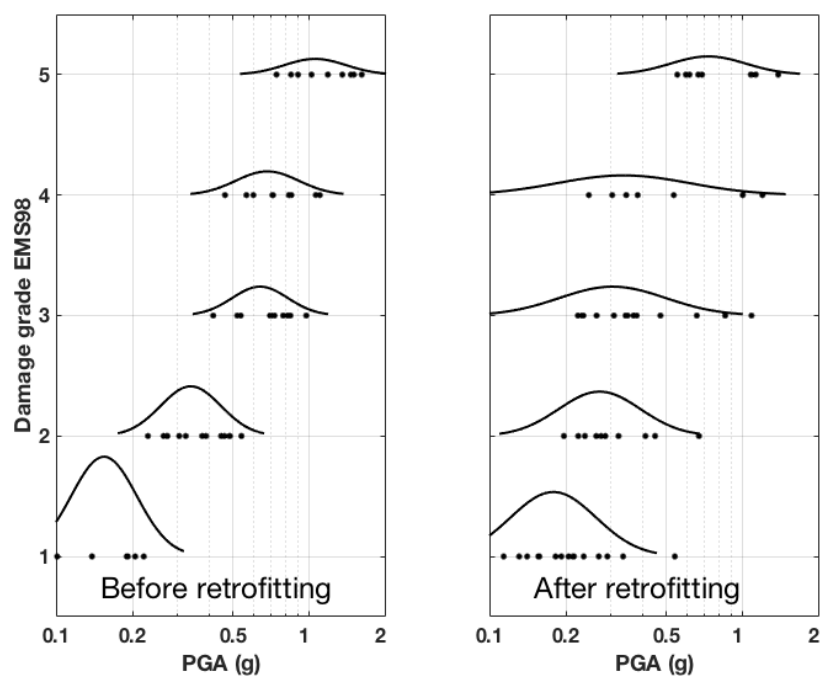

Figure 13. Lognormal distribution of the peak ground acceleration values for each damage grade

To compare the relation between the changes in the stiffness of the building subjected to strong motions with its displacement capacity, the drop in the natural frequency of each mode, normalized using the initial natural frequencies in Table 7, versus the inter-story drift in each direction is shown in Figure 14. Those values are also compared to an empirical model obtained from laboratory tests of a clay brick URM structure [27]. The different failure mechanisms of the URM building before and after the retrofit work can explain the differences seen in Figure 14. The pre-retrofit failure mechanism in the URM building is a result of local damage in the connection of the slabs with the URM walls, which results in an out-of-plane failure of the URM walls. The post-retrofit failure mechanism of the URM building, on the other hand, is governed by a soft story mechanism in the building involving the in-plane resistance from all the URM walls. The new stiff slabs link the URM walls and make them behave uniformly; therefore, the drop in the overall frequencies 
which is related to the overall stiffness of the building [27], and not some local effects, is higher after adding the stiff slabs.
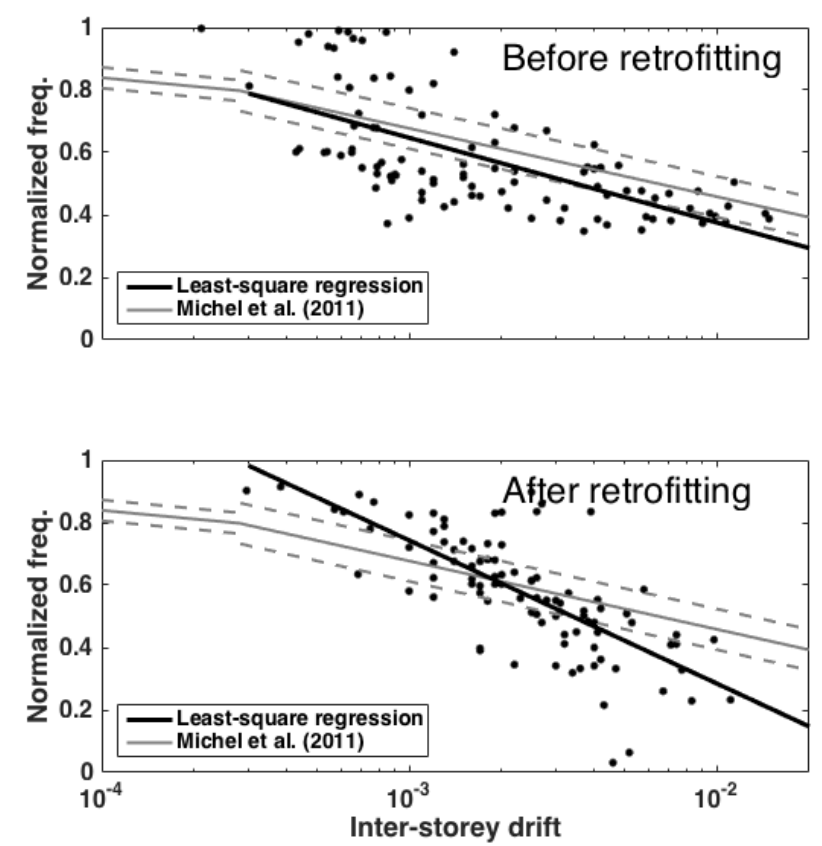

Figure 14. Drop in the modal frequencies (normalized) with the inter-story drift values

The comparison of the inter-story drift values from the pre- and post-retrofit numerical models can provide an idea about the change in the displacement capacity and ductility of the URM building, as a result of the retrofit work. Figure 15 shows the mean values of the inter-story drift at each damage grade (DG1 to DG4) along with the $68 \%$ confidence intervals of the data (mean plus/minus one standard deviation). It should be noted that the inter-story values for DG5 are not shown in this figure because this damage grade corresponds to the collapse of the building, and the inter-story drift values are difficult to be determined.
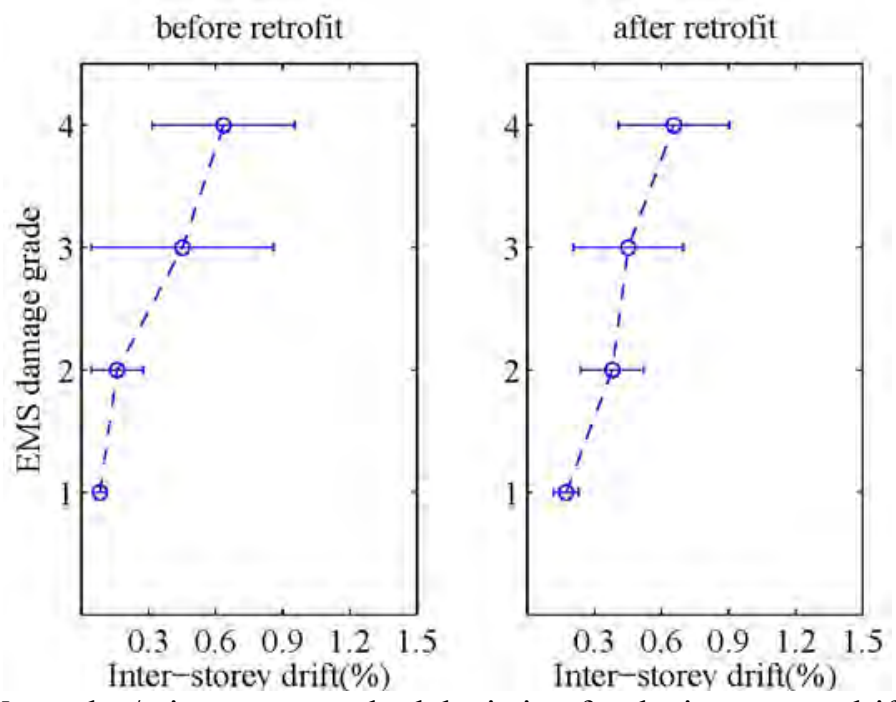

Figure 15. Mean plus/minus one standard deviation for the inter-story drift at each DG

If the damage grade 2 is considered as the yield point at which the URM building enters the nonlinear phase, and damage grade 4 is assumed to be the ultimate point before the building collapses (damage grade 5), the displacement ductility of the URM building before and after the retrofit work can be estimated from the mean values of the inter-story drift as shown in Table 8. 
Table 8. Change in the displacement capacity of the URM building

\begin{tabular}{|c|c|c|}
\hline ISD-mean values (\%) & Before retrofit & After retrofit \\
\hline DG2 & 0.16 & 0.38 \\
\hline DG4 & 0.64 & 0.66 \\
\hline $\begin{array}{c}\text { displacement ductility } \\
\text { from ISD }\end{array}$ & 4 & 1.7 \\
\hline
\end{tabular}

As seen in Table 8, although the average displacement capacity of the URM building has increased as a result of the retrofit work, the displacement ductility seems to be lower for the post-retrofit case. This could be explained by the fact that the new slabs have increased the overall stiffness of the building resulting in a structure with a higher strength but lower ductility.

\section{Discussion}

\subsection{Effect on resonance frequencies}

The numerical analyses show only a 3\% increase in the modal frequencies of the URM building after the retrofit work, whereas the ambient vibration study shows a $25 \%$ increase. In the model, the increase in the overall stiffness of the URM building has been counterbalanced by the increase in the mass, as a result of the new stiff slabs. In the ambient vibration tests, additional stiffness can be observed. Considering SSI effects in the recordings, this change in structural stiffness could be even larger. The stiffness of partition walls is naturally included in the observation and not in the numerical modeling but these non-structural elements cannot provide such a large stiffness and the model is already too stiff, so that this difference remains unexplained. This shows the difficulty to model such a complex structure and our remaining lack of knowledge in the interpretation and modeling of the dynamics of URM structures. This uncertainty in the frequency is important for the estimation of the seismic demand. If we consider a $35 \%$ frequency drop from the ambient vibrations level to the yield level [27], the "elastic" fundamental frequency from the experimental data would be $1.75 \mathrm{~Hz}$ in the initial state and $2.2 \mathrm{~Hz}$ in the final state. The elastic acceleration demand in the SIA261 code (zone 1, ground type C) would remain on the plateau at $1.7 \mathrm{~m} / \mathrm{s}^{2}$. However, with the same assumption, the displacement demand would vary from $1.4 \mathrm{~cm}$ in the initial state to $0.9 \mathrm{~cm}$ in the retrofitted state. This decrease of the displacement demand due to the stiffening would be more than $35 \%$, which is noticeable. Using the frequencies from the numerical modeling, no gain in the displacement demand is expected. This is, therefore, a conservative result that makes the modeling valid for the seismic assessment.

\subsection{Effect on mode shapes}

Using the experimental data, the expected diaphragm effect after adding the new slabs could be observed and, therefore, was used in the numerical modeling. The experimental data also showed an increased sensitivity to torsion due to this effect. However, the dynamic modeling proves that this added sensitivity does not play a role in the earthquake safety. This is due to the good symmetry of the walls that limits torsion.

Figures 6 and 15 show a change in the mode shape between the pre-retrofit numerical model and the one after retrofitting. The total lateral drift in the numerical model after the retrofitting work is governed by the inter-story drift of the first floor. This is different from the behavior of the numerical model before retrofit, in which the lateral drift has a uniform distribution over the height of the building. This difference in behavior shows that the retrofit has a clear effect on the overall seismic behavior of the URM building. Unlike the preretrofit structure, for which the failure mechanism is governed by the out-of-plane failure of the URM walls, the installation of the stiff slabs in the building creates a diaphragm effect for those walls. As a result, when the URM building is subjected to strong motions, all the elements contribute to the lateral load resisting system, and the failure mechanism transforms from a local to a global behavior. A higher drop in the normalized modal frequencies in the post-retrofit structure, shown in Figure 14 is a good evidence of this transformation, showing that a higher share of the URM elements contribute to the lateral load resisting system. 
From a displacement perspective, the post-retrofit structure has a higher displacement capacity (higher interstory drift values), but a lower displacement ductility. Overall, the safety with respect to the 35 scenarios performed in both states did not change much, although a slight improvement was noted (section 3.3).

\subsection{Other effects}

The ambient vibration experiment pointed out other effects that cannot be seen in the numerical modeling. The most relevant is probably soil-structure interaction that seems to play an important role in this case. Moreover, the effect of surface geology on the ground motion could be assessed with the measurements, although, it was shown not to be significant in the case of the studied building. Finally, the four tests showed that long-term stiffening occurred during the retrofitting. As a future recommendation, monitoring these effects with a seismometer installed before the start of the retrofitting work until 6 months after the end may allow us to understand such changes in a building being retrofitted.

\section{Conclusions}

A numerical modeling and ambient vibration measurements were used to assess the retrofitting measures conducted in an URM building aiming at improving its soundproofing and also its seismic behavior. The major part of the retrofitting work concerned the addition of a stiff slab at each floor. From the results of both the numerical modeling and the ambient vibration measurements, it is confirmed that the in-plane behavior of the slabs evolved from non-rigid floors with in-plane deformation to rigid floors with diaphragm effects. This will be relevant under earthquake only if the connections work well, something that could not be assessed from either the numerical modeling or the ambient vibration measurements. The numerical modeling pointed out that the failure mechanism of the URM building in the pre-retrofit status transformed from a local (out-of-plane) to a global (in-plane failure of the walls) behavior when subjected to strong motions. The numerical models also showed that the displacement capacity of the building increased as a result of the stiff slabs, and on average, higher inter-story drift values were observed for all the damage grades in the post-retrofit model. The ambient vibration measurements showed an increase of about $25 \%$ in the modal frequencies of the URM building due to the retrofitting work. However, this stiffness increase (or loss of flexibility) could not be explain with the modelling which is the strongest limitation of our study. Such a change has an influence on the seismic demand that the structure could resist. According to the scenarios performed with the numerical model, the seismic safety was only slightly improved: $50 \%$ of the scenarios end up with the same level of damage, while about $20 \%$ led to higher damage and $30 \%$ to lower damage. It should be mentioned that this study did not account for the local hazard that might influence the resulting safety for a given location.

Even if all discrepancies between the model and the observation could not be resolved, the simultaneous use of these tools allowed a better understanding and quantifying of the seismic vulnerability of the structure. This combination is necessary to assess existing buildings since their seismic behavior remains poorly known.

\section{Acknowledgements}

The authors are thankful to Philippe Guéguen and Mathieu Perrault from ISTerre at the University of Grenoble in France who provided the measurement instruments and helped for the measurements. The authors are also grateful to the Swiss Federal Office for the Environment for the financial support of the numerical modeling part and Mr Martial Chabloz from the office Chabloz \& Partenaires SA in Lausanne for providing the opportunity to perform the measurements of the building. 


\section{References}

[1] Asteris PG, Chronopoulos MP, Chrysostomou CZ, Varum H, Plevris V, Kyriakides N, et al. Seismic vulnerability assessment of historical masonry structural systems. Eng Struct 2014;62-63:118-34. doi:10.1016/j.engstruct.2014.01.031.

[2] SIA. Merkblatt SIA 2018 - Überprüfung bestehender Gebäude bezüglich Erdbeben. Zürich, Switzerland: 2004.

[3] Chung L-L, Yang Y-S, Lien K-H, Wu L-Y. In situ experiment on retrofit of school buildings by adding sandwich columns to partition brick walls. Earthq Eng Struct Dyn 2014;43:339-55. doi:10.1002/eqe.2347.

[4] Soyoz S, Taciroglu E, Orakcal K, Nigbor R, Skolnik D, Lus H, et al. Ambient and Forced Vibration Testing of a Reinforced Concrete Building before and after Its Seismic Retrofitting. J Struct Eng 2013;139:1741-52. doi:10.1061/(ASCE)ST.1943-541X.0000568.

[5] Hancilar U, Çaktı E, Erdik M. Earthquake performance assessment and rehabilitation of two historical unreinforced masonry buildings. Bull Earthq Eng 2012;10:307-30. doi:10.1007/s10518-011-9281-3.

[6] ElGawady MA, Lestuzzi P, Badoux M. In-Plane Seismic Response of URM Walls Upgraded with FRP. J Compos Constr 2005;9:524-35. doi:10.1061/(ASCE)1090-0268(2005)9:6(524).

[7] ElGawady MA, Lestuzzi P, Badoux M. Aseismic retrofitting of unreinforced masonry walls using FRP. Compos Part B Eng 2006;37:148-62. doi:10.1016/j.compositesb.2005.06.003.

[8] Vicente R, Rodrigues H, Varum H, Mendes da Silva J a. R. Evaluation of Strengthening Techniques of Traditional Masonry Buildings: Case Study of a Four-Building Aggregate. J Perform Constr Facil 2011;25:202-16. doi:10.1061/(ASCE)CF.1943-5509.0000164.

[9] Nayeri RD, Masri SF, Chassiakos AG. Application of Structural Health Monitoring Techniques to Track Structural Changes in a Retrofitted Building Based on Ambient Vibration. J Eng Mech 2007;133:131125. doi:10.1061/(ASCE)0733-9399(2007)133:12(1311).

[10] Tomazevic M, Lutman M, Velechovsky T. Aseismic strengthening of old stone-masonry buildings: is the replacement of wooden floors with R.C. Slabs always necessary? Eur Earthq Eng 1993;2:34-46.

[11] Brignola A, Podestà S, Pampanin S. In-plane stiffness of wooden floor. 2008 NZSEE Conf., 2008, p. 119.

[12] Lestuzzi P, Podestà S, Luchini C, Garofano A, Kazantzidou-Firtinidou D, Bozzano C, et al. Seismic vulnerability assessment at urban scale for two typical Swiss cities using Risk-UE methodology. Nat Hazards 2016;84:249-69. doi:10.1007/s11069-016-2420-z.

[13] Géolausanne. Microzonage de Lausanne 2012.

[14] Michel C, Guéguen P, El Arem S, Mazars J, Kotronis P. Full-scale dynamic response of an RC building under weak seismic motions using earthquake recordings, ambient vibrations and modelling. Earthq Eng Struct Dyn 2010;39:419-41. doi:10.1002/eqe.948.

[15] Snoj J, Österreicher M, Dolšek M. The importance of ambient and forced vibration measurements for the results of seismic performance assessment of buildings obtained by using a simplified non-linear procedure: case study of an old masonry building. Bull Earthq Eng 2013;11:2105-32. doi:10.1007/s10518-013-9494-8.

[16] Karbassi A, Nollet MJ. Performance-based seismic vulnerability evaluation of masonry buildings using applied element method in a nonlinear dynamic-based analytical procedure. Earthq Spectra 2013;29:399-426. doi:10.1193/1.4000148.

[17] Carden EP, Fanning PJ. Vibration Based Condition Monitoring: A Review. Struct Heal Monit 2004;3:355-77. doi:10.1177/1475921704047500.

[18] Bonnefoy-Claudet S, Cotton F, Bard P. The nature of noise wavefield and its applications for site effects studies. Earth-Science Rev 2006;79:205-27. doi:10.1016/j.earscirev.2006.07.004.

[19] Welch PD. The Use of Fast Fourier Transform for the estimation of Power Spectra: A Method based on time averaging over short, modified periodograms. IEEE Trans Audio Electroacoust 1967;15:70-3. 
[20] Brincker R, Zhang L, Andersen P. Modal identification of output-only systems using frequency domain decomposition. Smart Mater Struct 2001;10:441-5. doi:10.1088/0964-1726/10/3/303.

[21] Brincker R, Ventura CE, Andersen P. Damping Estimation by Frequency Domain Decomposition. 19th Int. Modal Anal. Conf., Kissimmee, Florida: 2001, p. 698-703.

[22] Goulet J-A, Michel C, Smith IFC. Hybrid probabilities and error-domain structural identification using ambient vibration monitoring. Mech Syst Signal Process 2013;37:199-212. doi:10.1016/j.ymssp.2012.05.017.

[23] Bard P. The $\mathrm{H} / \mathrm{V}$ technique: capabilities and limitations based on the results of the SESAME project. Bull Earthq Eng 2008;6:1-2. doi:10.1007/s10518-008-9059-4.

[24] Konno K, Ohmachi T. Ground-Motion Characteristics Estimated from Spectral Ratio between Horizontal and Vertical Components of Microtremor. Bull Seismol Soc Am 1998;88:228-41.

[25] Chatelain J-L, Guillier B, Guéguen P, Fréchet J, Sarrault J. Ambient Vibration Recording for SingleStation, Array and Building Studies Made Simple: CityShark II. Int J Geosci 2012;03:1168-75. doi:10.4236/ijg.2012.326118.

[26] Michel C, Guéguen P, Causse M. Seismic vulnerability assessment to slight damage based on experimental modal parameters. Earthq Eng Struct Dyn 2012;41:81-98. doi:10.1002/eqe.1119.

[27] Michel C, Zapico B, Lestuzzi P, Molina FJ, Weber F. Quantification of fundamental frequency drop for unreinforced masonry buildings from dynamic tests. Earthq Eng Struct Dyn 2011;40:1283-96. doi:10.1002/eqe. 1088 .

[28] Meguro K, Tagel-Din HS. Applied Element Method Used for Large Displacement Structural Analysis. J Nat Disaster Sci 2002;24:25-34.

[29] Tagel-Din H, Meguro K. Applied Element Method for Dynamic Large Deformation Analysis of Structures. J Struct Mech Earthq Eng JSCE 2000;17:215-24.

[30] Fry B, Benites R, Kaiser A. The Character of Accelerations in the Mw 6.2 Christchurch Earthquake. Seismol Res Lett 2011;82:846-52. doi:10.1785/gssrl.82.6.846.

[31] Guragain R, Warakanchana K, Mayourca P, Meguro K. Numerical Simulation of Masonry Structures under Cyclic Loading using Applied Element Method. University of Tokyo, 2006.

[32] Hill M, Rossetto T. Comparison of building damage scales and damage descriptions for use in earthquake loss modelling in Europe. Bull Earthq Eng 2008;6:335-65. doi:10.1007/s10518-007-9057-y.

[33] Grünthal G, Musson RMW, Schwartz J, Stucchi M. European Macroseismic Scale 1998. vol. 15. Luxembourg: Cahiers du Centre Européen de Géodynamique et de Séismologie; 1998.

[34] Lang K, Bachmann H. On the seismic vulnerability of existing unreinforced masonry buildings. J Earthq Eng 2003;7:407-26.

[35] SIA. SIA 266 Masonry. Zurich, Switzerland: Swiss Society of Engineers and Architects SIA; 2003.

[36] European Committee for Standardisation. Eurocode 6: Design of masonry structures. 1995.

[37] Lourenço PB. Experimental and numerical issues in the modelling of the mechanical behaviour of masonry. Struct. Anal. Hist. Constr. II, Barcelona: CIMNE; 1998, p. 57-91.

[38] Ambraseys NN, Smit P, Douglas J, Margaris B, Sigbjörnsson R, Olafsson S, et al. Internet site for European strong-motion data. Bolletino Di Geofis Teor Ed Appl 2004;45:113-29.

[39] Luzi L, Hailemikael S, Bindi D, Pacor F, Mele F, Sabetta F. ITACA (ITalian ACcelerometric Archive): A Web Portal for the Dissemination of Italian Strong-motion Data. Seismol Res Lett 2008;79:716-22. doi:10.1785/gssrl.79.5.716.

\section{Appendix}


Table A-1. Characteristics of ground motion records used in the nonlinear dynamic analyses. ${ }^{1}$ denotes aftershocks.

\begin{tabular}{|c|c|c|c|c|c|c|c|}
\hline & No. & $\mathrm{M}_{\mathrm{s}}$ & $\mathrm{R}(\mathrm{km})$ & Duration (sec.) & PGA $(\mathrm{g})$ & Soil & Site \\
\hline \multirow{37}{*}{ 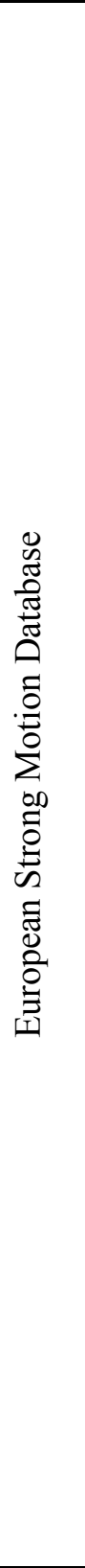 } & 55 & 6.6 & 23 & 15 & 0.36 & Rock & Friuli \\
\hline & 120 & 5.3 & 15 & 13 & 0.09 & Stiff & Friuli \\
\hline & 123 & 5.3 & 15 & 15 & 0.13 & Stiff & Friuli $^{1}$ \\
\hline & 126 & 5.9 & 21 & 10 & 0.45 & Stiff & Friuli $^{1}$ \\
\hline & 134 & 5.9 & 14 & 22 & 0.22 & Stiff & Friuli $^{1}$ \\
\hline & 146 & 5.9 & 14 & 15 & 0.35 & Stiff & Friuli $^{1}$ \\
\hline & 171 & 5.9 & 18 & 18 & 0.15 & Stiff & Basso Tirreno \\
\hline & 175 & 6.2 & 29 & 30 & 0.14 & Soft soil & Volvi \\
\hline & 198 & 7.1 & 21 & 18 & 0.18 & Rock & Montenegro \\
\hline & 199 & 7.1 & 16 & 18 & 0.45 & Stiff & Montenegro \\
\hline & 229 & 6.2 & 17 & 15 & 0.17 & Stiff & Montenegro $^{1}$ \\
\hline & 242 & 5.8 & 5 & 16 & 0.15 & Rock & Valnerina \\
\hline & 246 & 5.8 & 22 & 16 & 0.06 & Rock & Valnerina \\
\hline & 290 & 7.1 & 32 & 36 & 0.32 & Rock & Campano Lucano \\
\hline & 333 & 6.7 & 20 & 15 & 0.23 & Soft & Alkion \\
\hline & 334 & 6.7 & 19 & 15 & 0.29 & Soft & Alkion \\
\hline & 361 & 5.4 & 19 & 16.5 & 0.21 & Stiff & Umbria \\
\hline & 365 & 5.9 & 5 & 14 & 0.1 & Rock & Lazio Abruzzo \\
\hline & 384 & 5.3 & 6 & 6 & 0.15 & Soft & Lazio Abruzzo $^{1}$ \\
\hline & 413 & 5.8 & 10 & 9.5 & 0.21 & Stiff & Kalamata \\
\hline & 419 & 4.2 & 1 & 15 & 0.33 & Stiff & Kalamata $^{1}$ \\
\hline & 435 & 5.8 & 36 & 15 & 0.08 & Stiff & Kyllini \\
\hline & 559 & 5.1 & 24 & 18 & 0.11 & Stiff & Pyrgos \\
\hline & 591 & 5.6 & 3 & 14 & 0.26 & Soft & Umbria Marche \\
\hline & 593 & 5.6 & 13 & 15 & 0.54 & Stiff & Umbria Marche \\
\hline & 622 & 5.3 & 7 & 15 & 0.13 & Soft & Umbria Marche $^{1}$ \\
\hline & 766 & 5.4 & 12 & 15 & 0.32 & Rock & Umbria Marche $^{1}$ \\
\hline & 948 & 5.4 & 24 & 15 & 0.25 & Soft & Sicilia-Orientale \\
\hline & 990 & 5.3 & 15 & 12.6 & 0.13 & Rock & Lazio Abruzzo $^{1}$ \\
\hline & 1313 & 5.9 & 16 & 12 & 0.31 & Stiff & Ano Liosia \\
\hline & 1715 & 5.9 & 14 & 12 & 0.33 & Stiff & Ano Liosia \\
\hline & 2015 & 6.2 & 9 & 12 & 0.18 & Stiff & Kefallinia $^{1}$ \\
\hline & 3802 & 5.8 & 7 & 12 & 0.47 & Rock & Tirana \\
\hline & 5651 & 5.6 & 7 & 4.5 & 0.38 & Very Soft & Benja Luka \\
\hline & 6040 & 5.4 & 14 & 9.9 & 0.13 & Stiff & Kefallinia \\
\hline & 6115 & 6.6 & 17 & 12 & 0.27 & Rock & Kozani \\
\hline & 6131 & 4.1 & 12 & 16 & 0.28 & Soft & Lonian \\
\hline \multirow{6}{*}{ 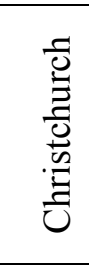 } & CBGS & 6.3 & 10.3 & 22 & 0.53 & Soft & Botanic Gardens \\
\hline & $\mathrm{CCCC}$ & 6.3 & 7.8 & 22 & 0.48 & Soft & College \\
\hline & LPCC & 6.3 & 6.4 & 22 & 0.88 & Rock & Lvttelton Port \\
\hline & NNBS & 6.3 & 12 & 22 & 0.76 & Very Soft & Brighton School \\
\hline & REHS & 6.3 & 9.4 & 22 & 0.72 & Soft & Resthaven \\
\hline & SHLC & 6.3 & 10.3 & 22 & 0.31 & Soft & Shirley Library \\
\hline \multirow{7}{*}{ 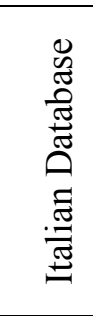 } & itaca013239 & 6.3 & 4.4 & 15.3 & 0.49 & Stiff & Aquila \\
\hline & itaca031518 & 6.0 & 5.2 & 8.5 & 0.32 & Stiff & Friuli \\
\hline & itaca072636 & 4.6 & 10 & 8 & 0.15 & Soft & Umbro- \\
\hline & itaca094025 & 6.1 & 12.1 & 13.7 & 0.50 & Very Soft & Umbria-Marche \\
\hline & itaca174737 & 5.4 & 5 & 11 & 0.68 & Stiff & Aquila $^{1}$ \\
\hline & itaca183453 & 6.8 & 33.3 & 24.8 & 0.19 & Stiff & Irpinia \\
\hline & itaca210440 & 4.9 & 10.6 & 10 & 0.19 & Stiff & Val Nerina \\
\hline
\end{tabular}

